\title{
Design of Breakwaters to Minimize Greenwater Loading on Bow Structures of Fixed Vessels
}

\author{
Lim Jun An ${ }^{1}$ and Mohammed Abdul Hannan 2,3,*(D) \\ 1 Marine Technology, Newcastle University in Singapore, Singapore 038986, Singapore; \\ 1700367@sit.singaporetech.edu.sg \\ 2 Faculty of Science Agriculture \& Engineering, Newcastle University, Newcastle upon Tyne NE1 7RU, UK \\ 3 Newcastle Research \& Innovation Institute Singapore (NewRIIS), Newcastle University, Newcastle upon \\ Tyne NE1 7RU, UK \\ * Correspondence: abdul.hannan@ncl.ac.uk
}

Citation: An, L.J.; Hannan, M.A. Design of Breakwaters to Minimize Greenwater Loading on Bow Structures of Fixed Vessels. Fluids 2021, 6, 212. https://doi.org/ $10.3390 /$ fluids 6060212

Academic Editors: Sheldon Wang and Vyacheslav Akkerman

Received: 16 July 2020

Accepted: 4 June 2021

Published: 8 June 2021

Publisher's Note: MDPI stays neutral with regard to jurisdictional claims in published maps and institutional affiliations.

Copyright: (c) 2021 by the authors. Licensee MDPI, Basel, Switzerland. This article is an open access article distributed under the terms and conditions of the Creative Commons Attribution (CC BY) license (https:// creativecommons.org/licenses/by/ $4.0 /)$.

\begin{abstract}
Greenwater (splashing of water on the deck) loading is a classical problem faced by designers of ship-shaped vessels, which becomes even worse when the vessel operates in harsh weather conditions for an extended period of time. Installation of breakwaters on the deck can play a crucial role in minimizing this impact. However, research on the design and optimization of the breakwater is still in its infancy, and this study aims at shedding further light on this area by proposing and analysing the effectiveness of three breakwater designs on a fixed box-shaped vessel. The commercial CFD software ANSYS Fluent is used for this investigation. The design model (without breakwater) was validated at first against experimental results of greenwater splashing, before performing the actual simulations with the proposed breakwater design. A vertical plate is used as the deck structure, and the greenwater pressure at several locations on that plate is measured to compare the effectiveness of various breakwater designs. Overall, breakwaters with openings (perforations, grillages, etc.) were found to be more effective in minimizing the pressure generated by the greenwater. Nevertheless, there is significant room for improvement on breakwater designs, and some topics for further research are also suggested in this regard.
\end{abstract}

Keywords: bow structures; breakwater design; CFD; greenwater; wave structure interaction

\section{Introduction}

With the increase of exploration activities at sea, mostly to exploit natural resources, including renewable energies, the development of various types of fixed and floating platforms for harsher and deeper offshore environments are facing newer challenges these days. Greenwater impact (forces exerted on the deck equipment and structure of floating bodies near the forward and back, due to the splashing of a large quantity of water from waves) is one such challenge that should be addressed to improve the safety of offshore operations. Among many deepwater offshore floating solutions, ship-shaped structures (FPSO, survey ships, etc.) are widely used to exploit oil and gas and other natural resources beneath the sea surface. The bow region of such platforms consists of various vital components, such as the flare tower, processing equipment, survey machinery and other topside erections. The operation of such platforms in calm weather conditions usually does not generate any significant problems, thanks to research and developments over the past decades. However, when these platforms are stationed in harsh offshore environments for an extended period, the long-term exposure to detrimental conditions, such as greenwater impact, can lead to significant structural and equipment damage which is of great concern with regards to the safety and operation of the platform. Hence, although minimizing the undesirable effects of greenwater on floating structures is a long-standing research issue, it is still developing new challenges as humankind is now exploring harsher and deeper offshore environments compared with the past. 
Dealing with greenwater is an important design consideration for ship-shaped structures since the medieval era. Evidence had shown that ships with high bulwarks at forward and aft ends were built in earlier days to reduce greenwater loading. Following the progression in technology, the assessment of the greenwater phenomenon has gradually advanced from qualitative to real science aspects. The effort by Newton [1] was the first systematic study in this field. A model ship was tested by him with five different above-water bow forms in regular head waves condition. Based on his visual observations, he concluded that the deck wetness could be categorized into "dry", "wet", or "very wet". Later, Tasaki [2] performed an experiment by mounting his ship model with a unique mechanism-a measurement trolly separately placed above the ship where he put a bucket and a pump connected to the ship to collect and measure the amount of water ingression in regular head waves. From the experiment, it was concluded that the relative wave motion is a crucial factor in the static and dynamic swell-ups on the ship bow area. Later, Ochi [3] used a statistical method to determine the slamming and shipping of greenwater. It was assumed that the exceedance of the freeboard by the relative wave motions has resulted in the same height of greenwater on the deck, and the pressure on it was equivalent to the static water head [4].

In the early 2000s, with the increase of oil and gas activities offshore, greenwater incidents with floating structures, for example, FPSOs, have been frequently reported [5]. There were 17 cases of greenwater incidents reported only in the UK regions alone between 1995 to 2000 [6]. Extensive experimental and numerical researches have been performed in this area since then, to understand and solve the significant effect of greenwater loading. Han et al. [7] experimented with an FPSO model in regular waves to evaluate the behaviours of greenwater. Kim et al. [8], on the other hand, used a potential flow model to study the behaviours of greenwater as well as the pressure on the deck and then presented a comparison between the simulation and the experimental results. For analysing such engineering problems, it is evident that the most accurate and reliable method is the model scale experiment, as it addresses most of the parameters and physics involved in the analyses. However, a convincing experimental result requires significant resources and time to perform. Therefore, with the advancement in technologies, computational simulation has become a popular alternative for the experimental method for these types of fluid-structure interaction problems $[9,10]$.

Among several computational techniques, Pham et al. [11] used the Lagrangian technique to simulate the water jet model and dam-breaking impact on a vertical wall. Similar methods were used by others $[12,13]$ to solve hydrodynamic problems. However, it was observed that the Lagrangian technique is not an excellent tool for modelling complex hydrodynamic issues such as greenwater behaviours. The Volume of Fluid (VOF) technique, on the other hand, has been used by several researchers to evaluate the effects of greenwater loading with success to some extent, when compared with the experimental findings [14]. Among some recent studies, the behaviour of greenwater impacting a fixed rectangular structure is studied by Lee et al. [15], and the flow kinematics is investigated with a series of experiments and computational fluid dynamic simulations. Liu et al. [16] studied violent breaking wave impacts on a vertical wall using a two-dimensional two-phase CFD model. Chen et al. [17] assessed the greenwater overtopping onto fixed ship-shaped FPSO models fitted with a "whaleback" or "duck-bill"-shaped forecastle using a numerical model based on OpenFOAM. They proposed a parameter based on the whaleback geometry and incoming wave, which can help to quickly estimate the effectiveness of such a forecastle shape. Chen et al. [18], on the other hand, performed 3D RANS CFD simulations for low and high freeboard Wigley hull models to understand the greenwater impact on deck at forward speed; however, no breakwater was considered.

As can be seen from the above discussion, the impact of greenwater behaviour with various types of bow shapes has been extensively studied over the years. However, the design of other remedial techniques, such as breakwater (barrier (such as the windshield of cars) to prevent the water from directly hitting the bow structures), is still in its infancy. 
Study on design and analysis of various types of breakwaters will therefore be able to generate significant insights for practical application and will help reduce the impacts of greenwater loading at the forward region of the vessel. The study presented here, in this regard, explored three breakwater designs-windshield, horizontal grillage and perforated breakwaters and performed a numerical study to analyse their performance on reducing the greenwater loading effects on the bow structures of a box-shaped fixed floating structure. The box-shaped floating structure was first generated without any breakwater, and the greenwater impact on that bare structure was validated against the experimental and numerical findings reported by Lim et al. [19]. The three breakwater designs were then added to that validated model, and their performance on reducing the greenwater impact was studied by performing numerical simulations. The analysis was carried out in ANSYS Fluent 19.2. A series of predefined regular head waves were simulated to represent the greenwater impacting the box ship model mounted with a breakwater. Then, greenwater pressures on nine different points on a vertical plate at the bow region, which acts as a bow structure, were recorded to evaluate the effectiveness of the three proposed breakwater designs.

\section{Methodology}

\subsection{Simulation Model without the Breakwaters}

The entire simulation domain used for this study (a) and a closeup view of the boxshaped fixed ship model with a vertical plate as the bow structure (b) is shown in Figure 1. It is the exact setup as used in [19] for their greenwater flow experiment. Their research was carried out in the Seoul National University's towing tank on a 1:100 scale model of typical full-load principal dimensions FPSO [20]. The freeboard (height of the box-shaped model above water), an essential criterion in the greenwater problem, was determined to be $1.5 \%$ of the length, as used in [21]. The locations of the pressure gauges used for the measurement are also marked in Figure $1 \mathrm{~b}$.

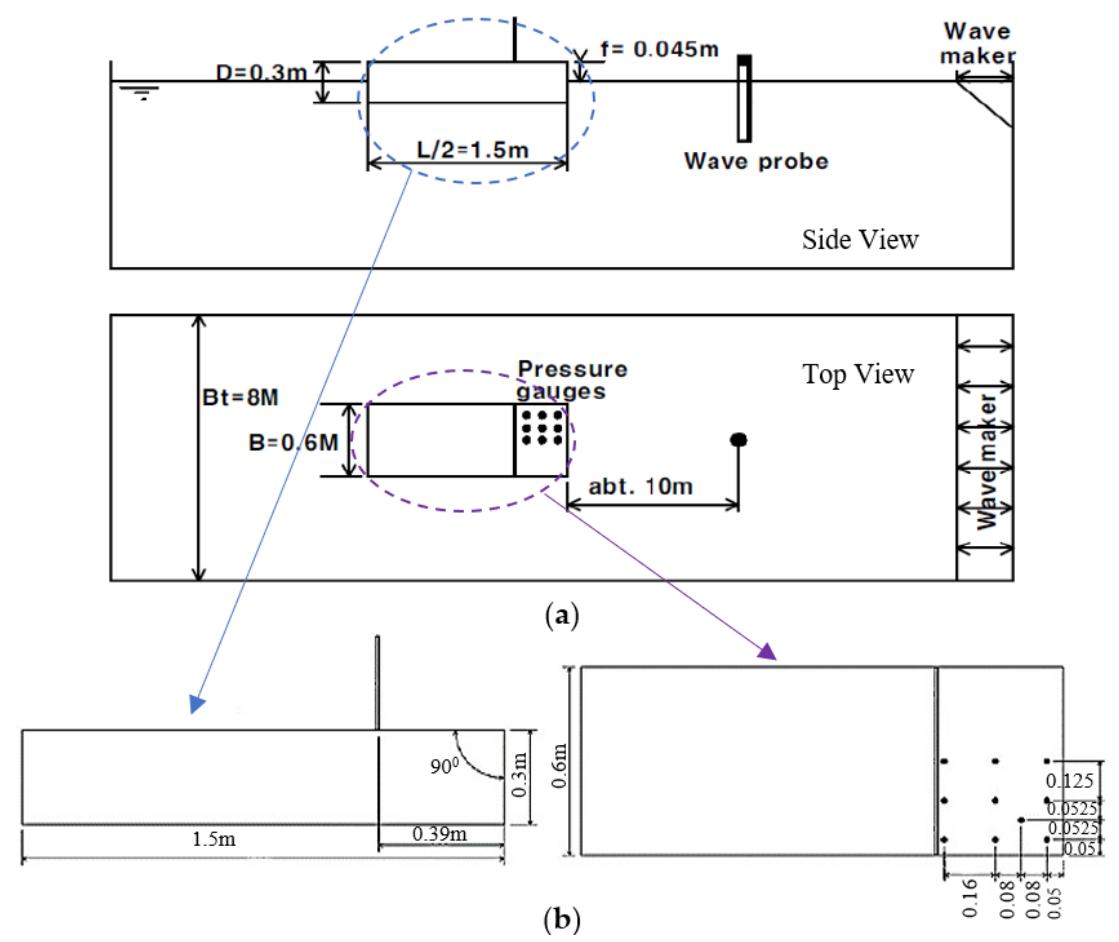

Figure 1. Simulation domain [19]: (a) entire domain, including wavemaker. Side view, followed by the top view; (b) box-shaped fixed ship model (as marked by dashed circles in (a)) with a vertical plate acting as deck structure at the bow region (all dimensions in $\mathrm{m}$ ). 
A series of regular head waves, as suggested in [19] for breakwater study, is presented in Table 1. Among these, the wave case with $\lambda=3.75 \mathrm{~m}$ and $A_{W}=0.1125 \mathrm{~m}$ is used for the current analysis to generate the waves creating the splashing greenwater. The numbering and relative positions of each pressure gauge (as shown in Figure 1b) are depicted in Figure 2. Later, the pressure exerted by the greenwater at two of these locations (P4 and P12) will be compared as a part of the validation study.

Table 1. Regular head wave conditions used for the simulations.

\begin{tabular}{cccc}
\hline $\mathbf{k}\left(\frac{\mathbf{H}_{\mathbf{W}}}{\lambda}\right)$ & $\boldsymbol{\lambda}$ & $A_{W}(\mathbf{m})$ & \\
\cline { 2 - 4 } & $\lambda=2.25 \mathbf{~}$ & $\lambda=3 \mathbf{m}$ & $\lambda=3.75 \mathbf{~ m}$ \\
\hline 0.04 & 0.045 & 0.06 & 0.075 \\
\hline 0.05 & 0.05625 & 0.075 & 0.09375 \\
\hline 0.06 & 0.0675 & 0.09 & 0.1125 \\
\hline
\end{tabular}

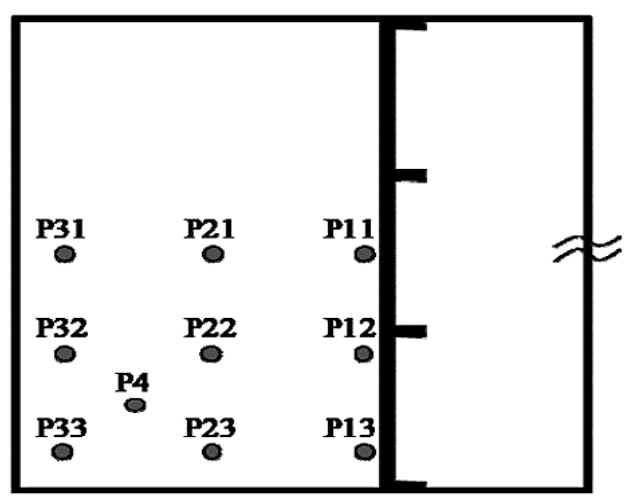

Figure 2. Locations of pressure measurement points on the deck.

\subsection{Design of Breakwaters}

The DNVGL (Det Norske Veritas Germanischer Lloyd) guidelines [22] is one of the commonly established design standards for breakwaters. This guideline is followed in this study to design the three intended breakwaters. As the rule dictates, the breakwater has to be located such that its upper edge at the centreline is not less than $H_{B} / \tan 20^{\circ}$ forward of the aft edge of the forecastle deck, as shown in Figure 3 (the distance indicated by the blue line). Here, $H_{B}$ is the height of the breakwater.

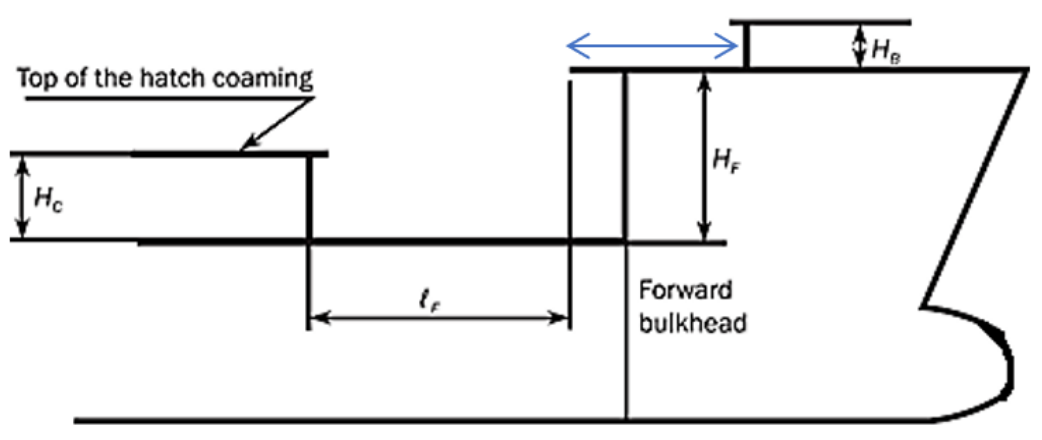

Figure 3. Breakwater location in forecastle arrangement.

Besides the location, the guideline also specified that the breakwater's width should be at least equal to the width of the area intended for the carriage of deck cargo. The minimum average height of the breakwater in $\mathrm{m}$ should be calculated using the formula in 
Equation (1), and this height needs not be more than the maximum height of the deck cargo stowed between the breakwater and $15 \mathrm{~m}$ aft of it.

$$
h_{w, \min }=0.6\left[b_{d} C_{w}-\left(Y_{b}-T_{S C}\right)\right]
$$

Here, $Y_{b}=\mathrm{y}$ is the coordinate of the bottom line of the wave breaker, in metres. $C_{w}=$ waterplane coefficient. $T_{S C}=$ scantling draught in metres. $b_{d}=$ distribution factor, defined as $1.0+2.75\left(\frac{\frac{x}{L}-0.45}{C_{B}+0.2}\right)^{2} \cdot C_{B}=$ block coefficient.

For example, the average height $h_{W}$ of whalebacks or turtle decks shall be determined, as illustrated in Figure 4.
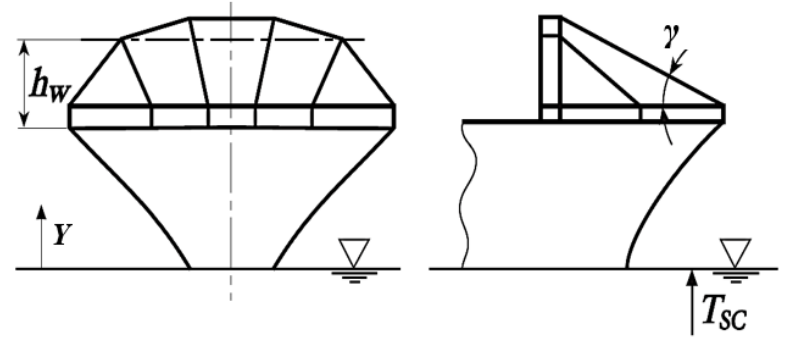

Figure 4. Breakwater height illustration for turtle decks (DNV-GL 2015).

Therefore, for the design of three intended breakwaters, the location, height and inclination angles $(\gamma)$ are determined following this DNV-GL guideline, and a confronting angle $(\theta)$ of 120 degrees (please refer to Figure 5 ) was selected. The vertical plate that is used as the bow structure (as described in Section 2.1) is kept the same, and the breakwaters are added in front of this bow structure to create new models for numerical analysis. The width of this vertical bow structure and the breakwaters are kept the same. More details on the designs of the three breakwaters are presented in the following three subsections.

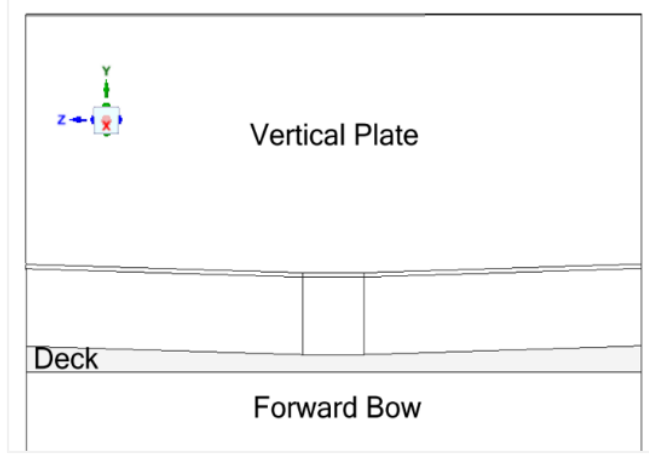

(a)

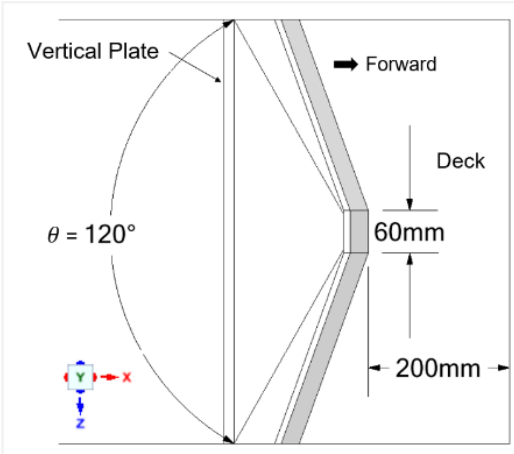

(b)

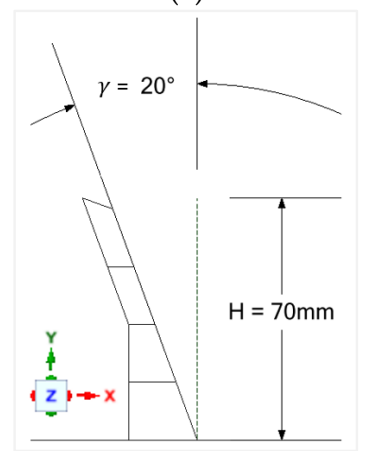

(c)

Figure 5. Design of windshield breakwater: (a) front view; (b) top view; (c) side view. 


\subsubsection{Windshield Breakwater}

The design of windshield breakwater was inspired by Buchner's [4] traditional vshape breakwater and the windshield of a car. According to Buchner, when the waterfront hits the traditional v-shape breakwater, it causes the forward area to be flooded and results in water flowing over the breakwater due to the vertical run-up. Henceforth, it was thought that the vertical run-up of greenwater could be reduced by changing the inclination angle of the breakwater to $20^{\circ}$.

For simplicity of the calculations, the calculated height and location of the breakwater were rounded to $70 \mathrm{~mm}$ and $200 \mathrm{~mm}$ (from the fore-end of the modelled box ship), respectively. Figure 5 further illustrates the design of this windshield breakwater.

\subsubsection{Horizontal Grillage Breakwater}

The horizontal grillage breakwater was inspired by the design of the grillage fence with uniform angles; however, the basic geometry (width, height, location, confronting and inclination angle) is the same as that of the windshield breakwater. Parameters that determine the grillage design include the width, thickness and gaps between each grillage. For this study, the half-width, thickness and gap of the horizontal grillages were chosen to be $270 \mathrm{~mm}, 5 \mathrm{~mm}$, and $10 \mathrm{~mm}$, respectively. These dimensions of the horizontal grillage breakwater are shown in Figure 6 for the front view only, as the other two views are similar to that of the windshield breakwater.

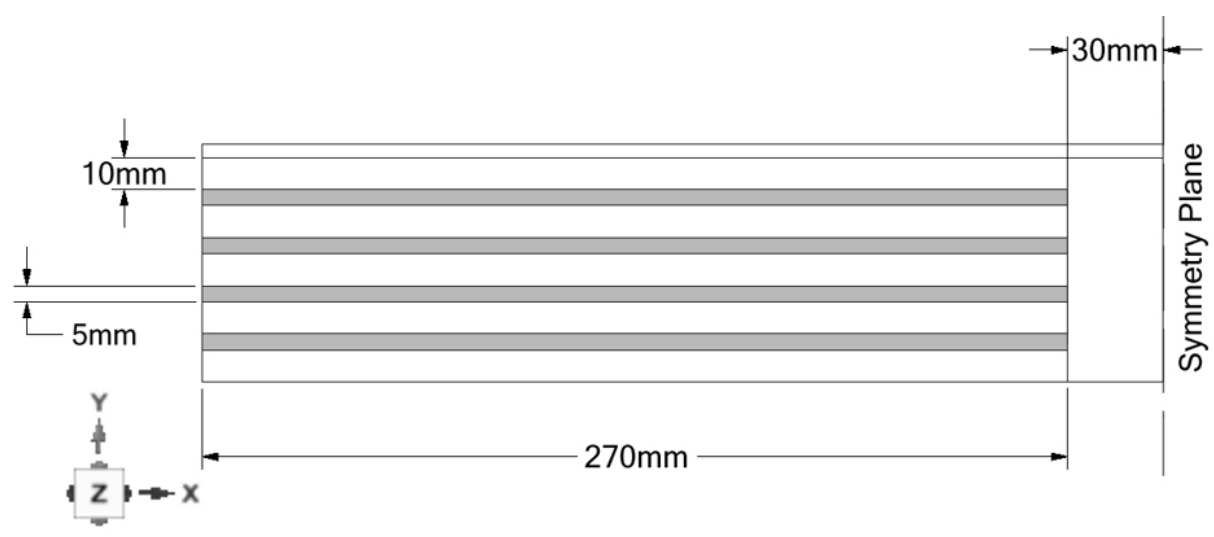

Figure 6. Front view of horizontal grillage breakwater (half of the length about the symmetry plane).

\subsubsection{Perforated Breakwater}

This design of the breakwater is exactly the same as that of the windshield breakwater, except that, instead of solid plates, it now has perforations in it. The introduction of holes to the breakwater was inspired by Varyani et al. [23], and the main parameters that determine this design include the locations and diameter of the perforations on the plate. Figure 7 shows the half-width symmetric front view of the design with the essential dimensions.

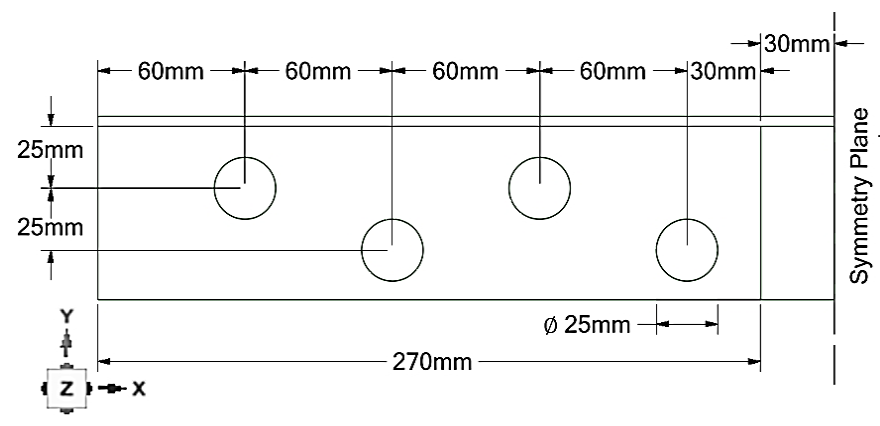

Figure 7. Front view of the perforated breakwater (half of the length about the symmetry plane). 
Four geometric models of the box ship are then developed-without breakwater, with windshield breakwater, with horizontal grillage breakwater and with perforated breakwater for numerical investigations. It should also be highlighted again that all these models have a vertical plate that acts as the bow structures, and in the case of "without breakwater" design, this vertical plate bow structure is directly exposed to the greenwater. Figure 8 shows all these four box-shaped ship models fitted with the vertical plate and breakwaters (except for the basic model which has no breakwater).
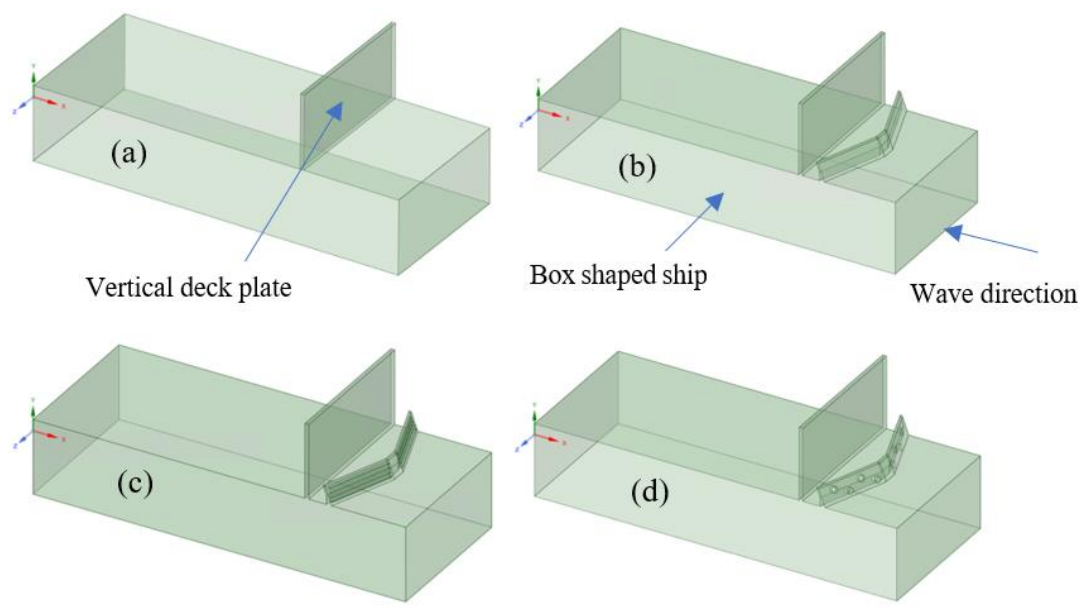

Figure 8. Box ship model developed for this study: (a) no breakwaters; (b) windshield breakwater; (c) horizontal grillage breakwater; (d) perforated breakwater.

\subsection{Numerical Modelling}

The governing equations of motion for incompressible flow expressed by the conservation of mass and momentum, which are widely used to simulate fluid flow, are:

$$
\begin{gathered}
\frac{\partial u}{\partial x}+\frac{\partial v}{\partial y}+\frac{\partial w}{\partial z}=0 \\
\frac{\partial(\rho u)}{\partial t}+\nabla \cdot(\rho \mathrm{uV})=-\frac{\partial p}{\partial x}+\rho f_{x} \\
\frac{\partial(\rho v)}{\partial t}+\nabla \cdot(\rho \mathbf{v V})=-\frac{\partial p}{\partial y}+\rho f_{y} \\
\frac{\partial(\rho w)}{\partial t}+\nabla \cdot(\rho w \mathbf{V})=-\frac{\partial p}{\partial z}+\rho f_{z}
\end{gathered}
$$

where $\rho$ is the fluid density, $\mathrm{p}$ is the pressure, $\mathrm{u}, \mathrm{v}$ and $\mathrm{w}$ are the velocity components in $\mathrm{x}, \mathrm{y}$ and $\mathrm{z}$ directions, $\nabla$ is the divergence, $\mathrm{V}$ is the isotropic tensor, $\mathrm{f}_{\mathrm{x}}, \mathrm{f}_{\mathrm{y}}, \mathrm{f}_{\mathrm{z}}$ are the body forces per unit mass in $\mathrm{x}, \mathrm{y}$, and $\mathrm{z}$-direction, respectively.

The problem is solved under the Eulerian-Eulerian framework using the ANSYS Fluent 19.2 Volume of Fluid (VoF) model. The implicit formulation with a volume fraction cutoff of $1 \times 10^{-6}$ is used for volume fraction parameters. Direct Numerical Simulation (DNS) is performed to solve the Navier-Stokes equations in 3D keeping the mesh size around the model surface near to the Kolmogorov microscale. Inside the VoF model, the "open channel flow" and "open channel wave boundary conditions" sub-models are used to define the simulation inlet, outlet and atmosphere following the experimental setup in [19]. The tracking of the interface between the phases ( $p$, the primary phase (air); q, the secondary phase (water)) is accomplished by the solution of a continuity 
equation. The equation has the following form for the qth phase [24] (ANSYS Fluent Tutorial Section 16.3.2):

$$
\frac{1}{\rho_{q}}\left[\frac{\partial\left(\alpha_{q} \rho_{q}\right)}{\partial \mathrm{t}}+\nabla \cdot\left(\alpha_{q} \rho_{q} \overline{V_{q}}\right)=\mathrm{S}_{\alpha q}+\sum_{p=1}^{n}\left(\dot{m}_{p q}-\dot{m}_{q p}\right)\right]
$$

where $\dot{m}_{q p}$ is the mass transfer from phase $\mathrm{q}$ to phase $\mathrm{p}$ and $\dot{m}_{p q}$ is the mass transfer from phase $\mathrm{p}$ to phase q. $\mathrm{S}_{\alpha q}$ is the source term and $\alpha_{q}$ is the volume fraction, respectively, for phase q. The volume fraction equation is not solved for the primary phase; it is computed based on the following constraint:

$$
\sum_{q=1}^{n} \alpha_{q}=1
$$

The corresponding momentum balance equation for this simulation is [24] (ANSYS Fluent Tutorial Section 16.3.2):

$$
\frac{\partial\left(\alpha_{q} \rho_{q} V_{q}\right)}{\partial \mathrm{t}}+\nabla \cdot\left(\alpha_{q} \rho_{q} \overline{V_{q} V_{q}}\right)=-\alpha_{q} \nabla \mathrm{p}+\nabla \cdot \bar{\tau}_{q}+\alpha_{q} \rho_{q} \bar{g}+\sum_{p=1}^{n}\left(\dot{\bar{R}}_{p q}+\dot{m}_{p q} \bar{V}_{p q}-\dot{m}_{q p} \bar{V}_{q p}\right)
$$

To consider the effect of surface tension along the interface, "surface tension force modelling" is set up in the phase interaction section of ANSYS. Water is considered at a temperature of 25 degree, and surface tension for water and air is taken as 72 miliNewton per meter. The "Continuum Surface Force Model" is used with a constant surface tension coefficient of 72. In this model, the surface tension is interpreted as a continuous, threedimensional effect across the interface, and the effect of surface tension is modelled by adding a source term in the momentum equation. More details in this regard can be found in [24].

As the CFD simulations are time-consuming, the advantage of the model symmetry is exploited, and only half of the domain is simulated to reduce computational efforts. A damping zone of $3750 \mathrm{~mm}$ was placed near the end of the simulation domain, and the water depth is set to $3500 \mathrm{~mm}$ as in [19]. The simulation model is constructed in ANSYS Spaceclaim, and various dimensions of the domain model are shown in Figure 9.

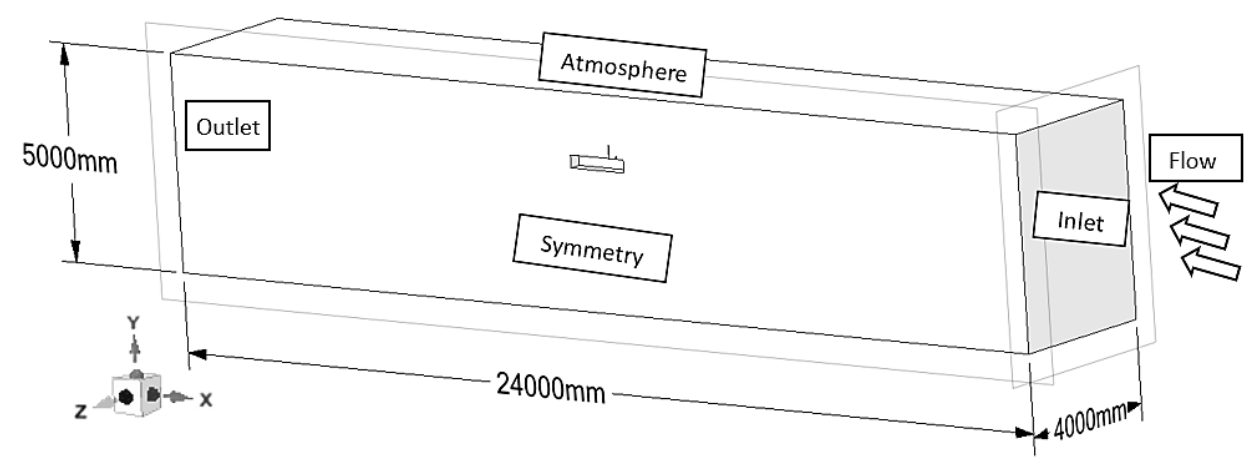

(a)

Figure 9. Cont. 


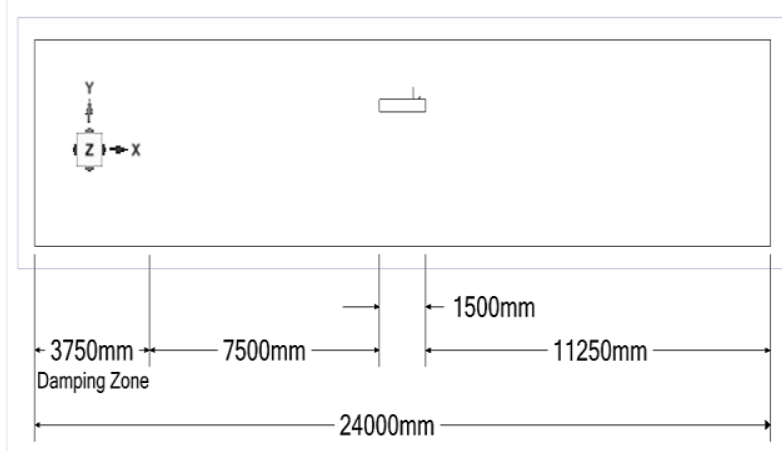

(b)

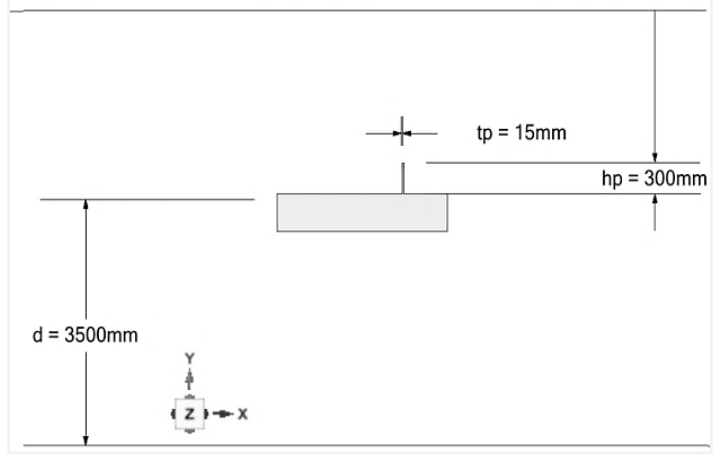

(c)

Figure 9. Sketch of the simulation domain (not to scale): (a) 3D view of symmetric domain; (b) side view of the entire domain; (c) closeup view of the box ship model with various dimensions.

Tetrahedral meshing with a "patch conforming" algorithm is used for discretizing the domain. The entire domain can be divided into three regions based on the grid density. The outermost region is meshed using an element size of $0.36 \mathrm{~m}$, as shown in Figure 10a. After that, a significant area around the box-shaped ship is discretized using an element size of $0.025 \mathrm{~m}$ (Figure 10b). Finally, the core region of the domain, including the ship, breakwater and flat-plate, where the interaction is most critical, is meshed with elements of $0.005 \mathrm{~m}$ size (Figure 10c). Besides, a target skewness of 0.5 was selected to improve the quality of the meshes. Overall, the total number of elements was near 1.7 million. Lim et al. [19], on the other hand, used a structured mesh with a minimum size of approximately $0.004 \mathrm{~m}$, and the total number of elements was around 1.3 million.

For the multi-phase VOF open channel flow, the transient simulation was performed as the simulation is expected to be highly unsteady. In the multi-phase selection, phase one is air, and phase two is liquid water. The densities of air and liquid water were set at $1.225 \mathrm{~kg} / \mathrm{m}^{3}$ and $998.2 \mathrm{~kg} / \mathrm{m}^{3}$, respectively. The boundary condition for the atmosphere was established at the pressure outlet to allow open channel flow. Inlet and outlet conditions were set as open channel flow with a depth of $3500 \mathrm{~mm}$. The Third Order Stokes wave theory was applied to achieve the wave steepness of 0.06 , as shown in Table 1 . With reference to Table 1, the wave height and wavelength were taken as $0.225 \mathrm{~m}$ and $3.75 \mathrm{~m}$, respectively. A hybrid initialization was then chosen to be computed from the inlet boundary condition. Based on visual convergence studies, twenty iterations per time step were deemed sufficient to achieve reasonably good residuals $\left(1 \times 10^{-6}\right)$. As this simulation of wave studies requires comparison studies with a short period, the time step size (s) was set at 0.001 to analyse the results. 


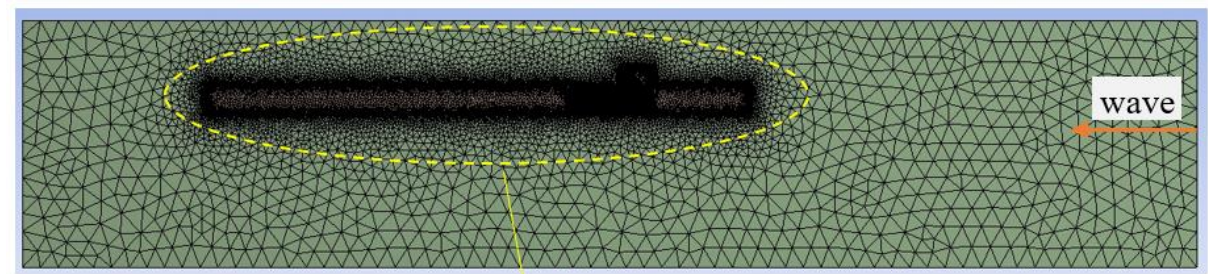

(a)

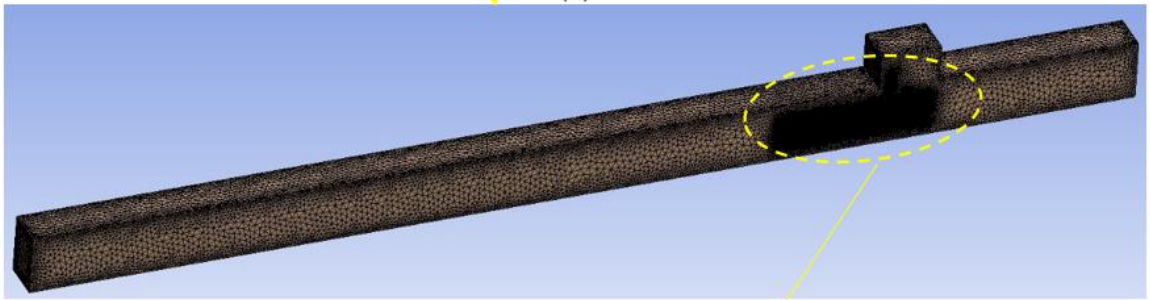

(b)

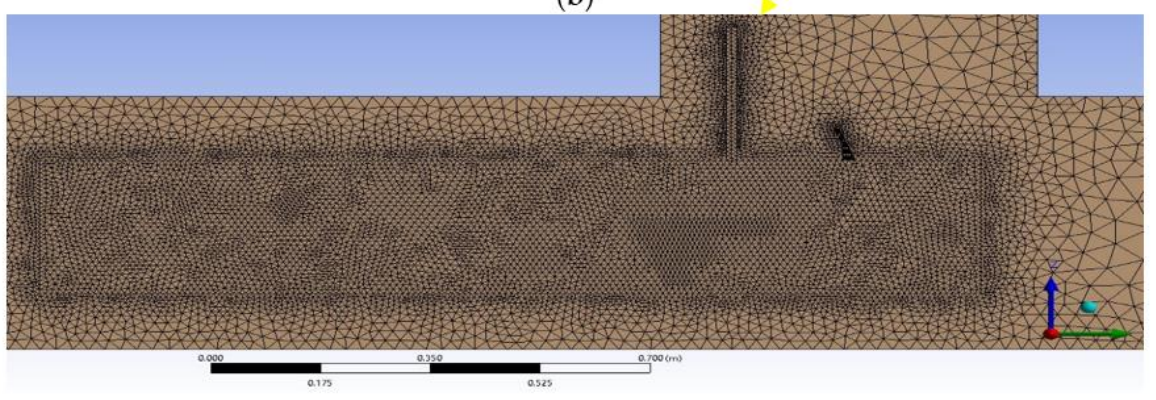

(c)

Figure 10. Meshing of the simulation domain: (a) 2D sectional view of the domain; (b) 3D view of the intermediate denser mesh region; (c) 2D sectional view of the core denser mesh region (the box ship with flat plate and breakwater).

The experimental study of Pham [25] shows that a vertical plate with attached load cells is more suitable for measuring the pressure while studying the impact of greenwater loading. As such, in this simulation, nine pressure measurement points were modelled on the vertical plate, which represents the bow structure. These pressure measurements will later be analysed to understand the effectiveness of the three proposed breakwater designs on minimizing the greenwater loading acting on the vertical plate. The arrangement of these pressure measurement points is shown in Figure 11. However, it should be noted that for the validation study, the pressure measurement points on the deck (as introduced in Figure 2) were used instead, following the original experimental setup.

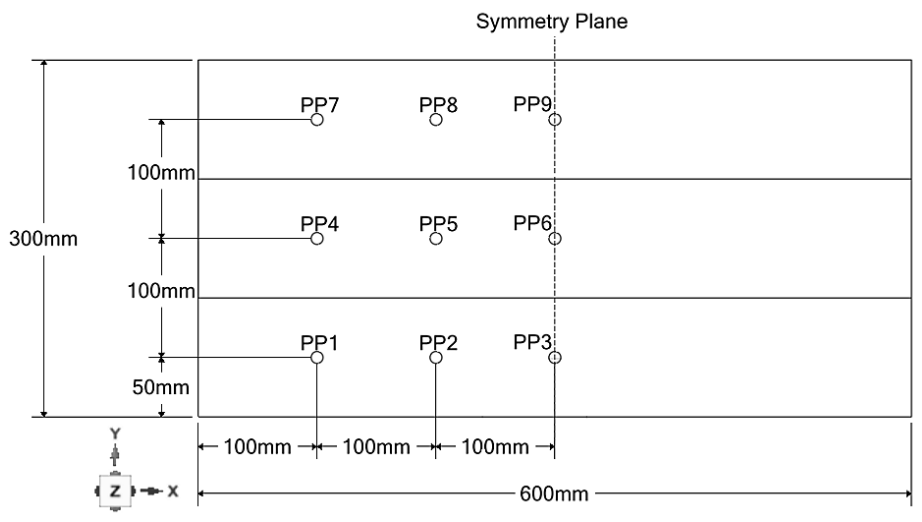

Figure 11. Arrangement of pressure measurement points for performance analysis of various breakwater designs. 


\section{Results and Discussions}

Among the four models developed for this study, the box ship model without a breakwater was first analysed and validated with the experimental findings in [19]. After that, the other three simulation models were run following this validated numerical setting, and the results for all four models were then compared and analysed to understand the effectiveness of the proposed breakwater designs.

\subsection{Validation of the Numerical Model}

In the experimental analysis performed by Lim et al. [19], to understand the impact of bow shape on greenwater behaviour, the experimental results for three different FPSO bow shapes in regular head waves were analysed and compared to each other. Among those, one of the bow designs was box-shaped, which is reproduced in the present study. Lim et al. placed a few pressure measurement sensors on the deck exposed to greenwater (as shown in Figure 2). To validate the present simulation model, the pressure calculated at locations "P4" and "P12" during the experiment were compared with the simulated pressure from this study. The comparison results are shown in Figures 12 and 13. As can be seen, the simulation results from the current analysis match quite well with the experimental values, as compared to other previous numerical analyses. The pressures at other locations show similar trends with the results as already presented in Lim et al. [19].

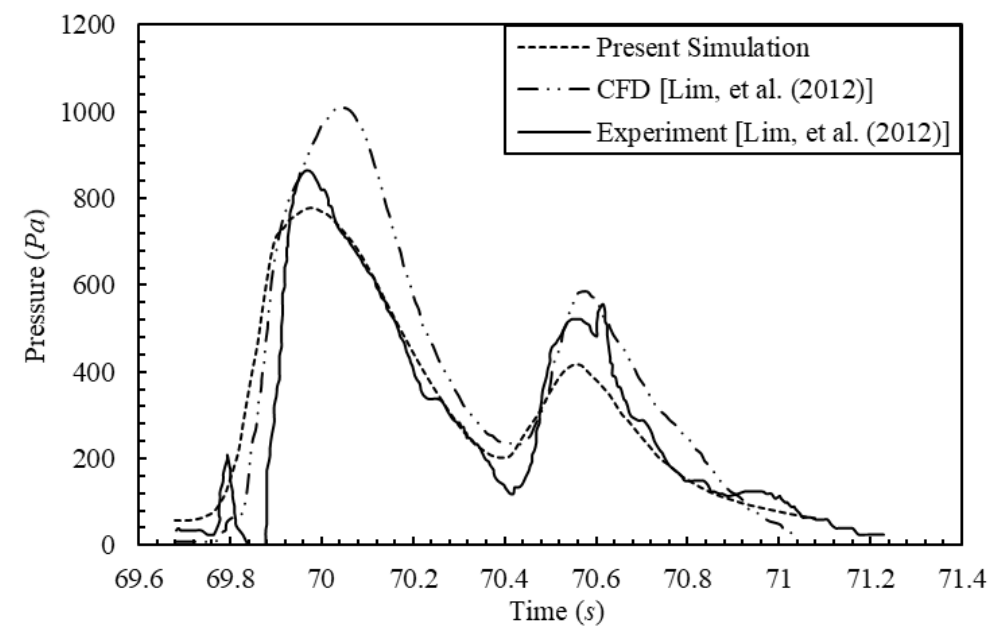

Figure 12. Comparison of pressures at location P4 on the deck $(A w=0.1125 \mathrm{~m}, \lambda=3.75 \mathrm{~m})$.

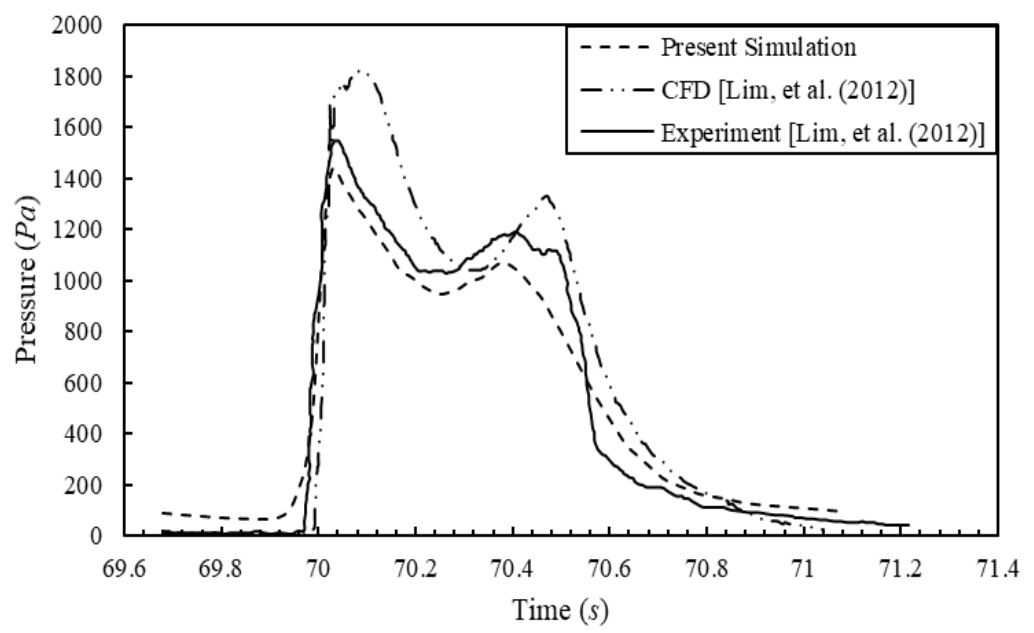

Figure 13. Comparison of pressures at location P12 on the deck $(A w=0.1125 \mathrm{~m}, \lambda=3.75 \mathrm{~m})$. 
It should also be noted that, apart from the mesh presented in Figure 10, two other meshes, slightly coarser (1.4 million elements) and finer ( 2 million elements), were also prepared by changing the sizes of the inner and intermediate core elements. Results obtained from the finer mesh model were found to be in good agreement with the results as presented above (which were obtained using the mesh presented in Figure 10), whereas results from the coarser mesh model varied noticeably, especially the pressure peaks were significantly lower. Based on this observation, the meshing arrangement shown in Figure 10 is used for the rest of the analysis presented in this paper.

Besides the comparisons of pressures at different points, snapshots of the greenwater behaviours on deck at two different time steps for both the experimental and simulation study were also compared. As depicted in Figure 14, the greenwater splashing for current simulations matches fairly well with both the experimental and other CFD simulations, except that the mesh resolutions are coarser in the present simulation study. Besides, a slight lag on the flow movement can be observed for the 2/8 T time step (which is $69.82 \mathrm{sec}$ ), which is also visible in Figure 11. This discrepancy might be attributed to the associated numerical error due to the conversion of the experimental setup to the simulation model.

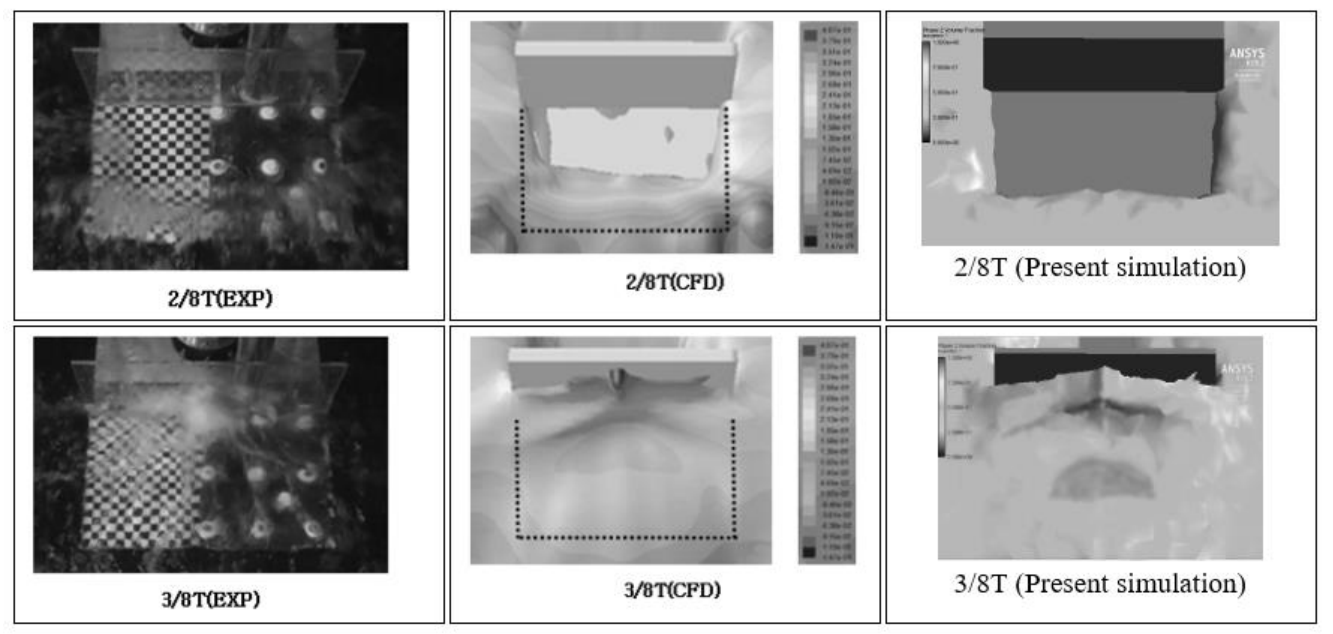

Figure 14. Comparisons of greenwater behaviours on the deck at various time instants: experiment (column 1) and CFD (column 2) from [19] vs. present simulation (column 3) results.

\subsection{Influence of Various Breakwaters on Greenwater Effects}

The associated setup of the validated model in Section 3.1 is then used to simulate the other three models with different breakwater designs. The influence of breakwaters on greenwater behaviour and associated impacts are analysed in this subsection by comparing the greenwater-generated pressure on the vertical deck plate for all four design models. As shown in Figure 11, a total of nine pressure measurement points were created on the plate in this regard.

Figure 15 depicts the dynamic pressure variation at point "PP2" for all four design cases, whereas Figure 16 shows the same results at point "PP3". As can be seen, the reduction in pressure due to the addition of breakwater is quite significant, irrespective of the type of breakwater used and the measurement point locations. Among the three breakwater designs proposed, the perforated breakwater appears to be most effective in terms of dynamic pressure reduction compared to the other two designs at the location "PP2", which is halfway in between the centreline and corner of the box ship. However, the horizontal grillage breakwater appears to be the most effective in reducing the impact of greenwater at the centreline of the ship (PP3), as it produces the least amount of pressure on the deck structure at this particular point. The windshield breakwater, on the other hand, appears to be the least effective in this case. Therefore, it can be said that the introduction of openings on the breakwater plates rather than keeping it solid appears to improve 
the controlling of the greenwater impact. However, the locations and designs of those perforations will significantly impact the pressure variations across the deck, and further study is necessary to reach meaningful conclusions in this regard.

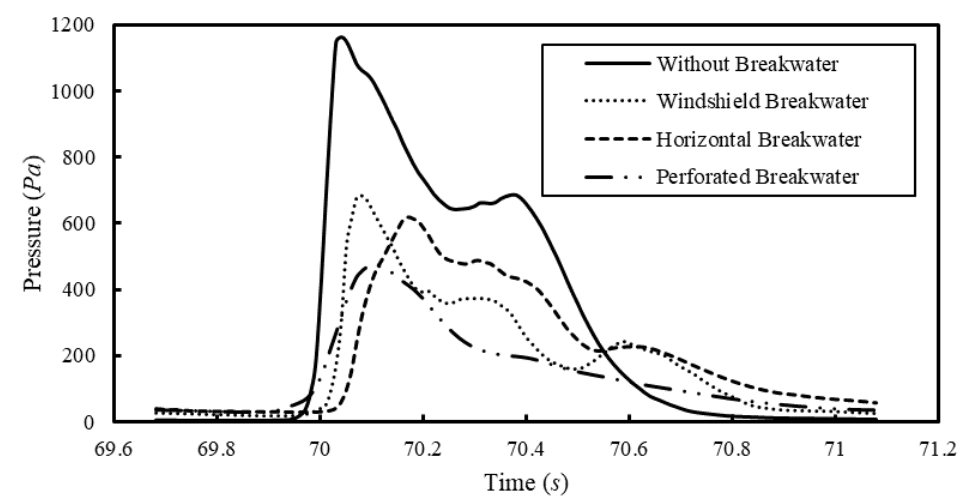

Figure 15. Impact of breakwaters on dynamic greenwater pressure variation at "PP2" on the vertical deck plate $(A w=0.1125 \mathrm{~m}, \lambda=3.75 \mathrm{~m})$.

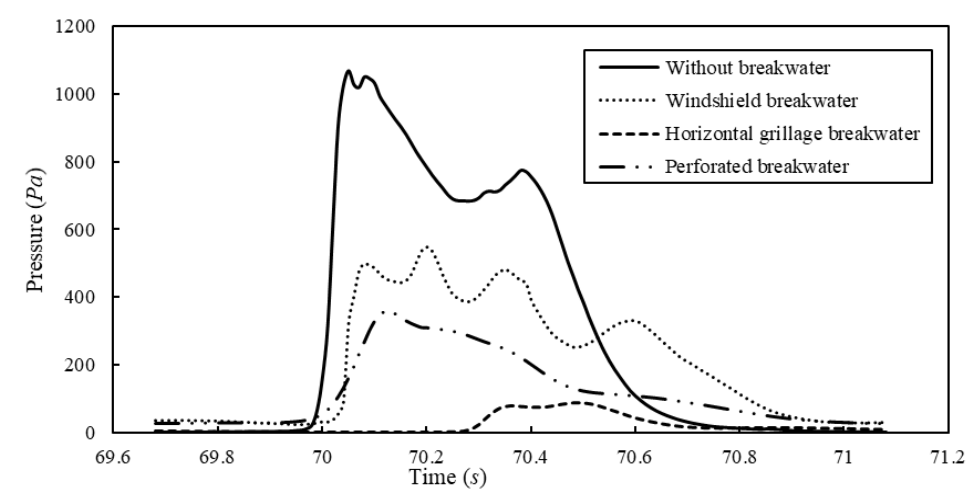

Figure 16. Impact of breakwaters on dynamic greenwater pressure variation at "PP3" on the vertical deck plate $(A w=0.1125 \mathrm{~m}, \lambda=3.75 \mathrm{~m})$.

To further explain the dynamic pressure variation as plotted in Figures 15 and 16, the instantaneous greenwater splashing at three different time steps for the three breakwater designs is presented in Figure 17. As can be seen, at the time step of $69.68 \mathrm{~s}$, the three breakwater designs have accumulated a significant amount of water in between the breakwater and vertical plate, which occurred due to the flat deck surface design. In reality, the deck of a vessel is designed in a slight concave shape to allow the draining of water overboard. Now, if the snapshots at $70.06 \mathrm{~s}(3 / 8 \mathrm{~T})$ for these three breakwater designs are compared with the $3 / 8 \mathrm{~T}$ snapshot for the without breakwater design in Figure 14, it can be seen that the three breakwater designs have effectively reduced the greenwater loading on the vertical plate. In comparison, the greenwater behaviours on the windshield and perforated breakwaters have shown resemblance in terms of the take-off angle of the over-riding water jet. In contrast, the greenwater on the horizontal grillage breakwater appears to be disrupted, which causes loss of energy in the fluid flow. This results in a reduction in the greenwater pressure force in the subsequent timestep for this grillage design (Figure 16), although the amount of water hitting the vertical wall is nearly the same for all three designs. 


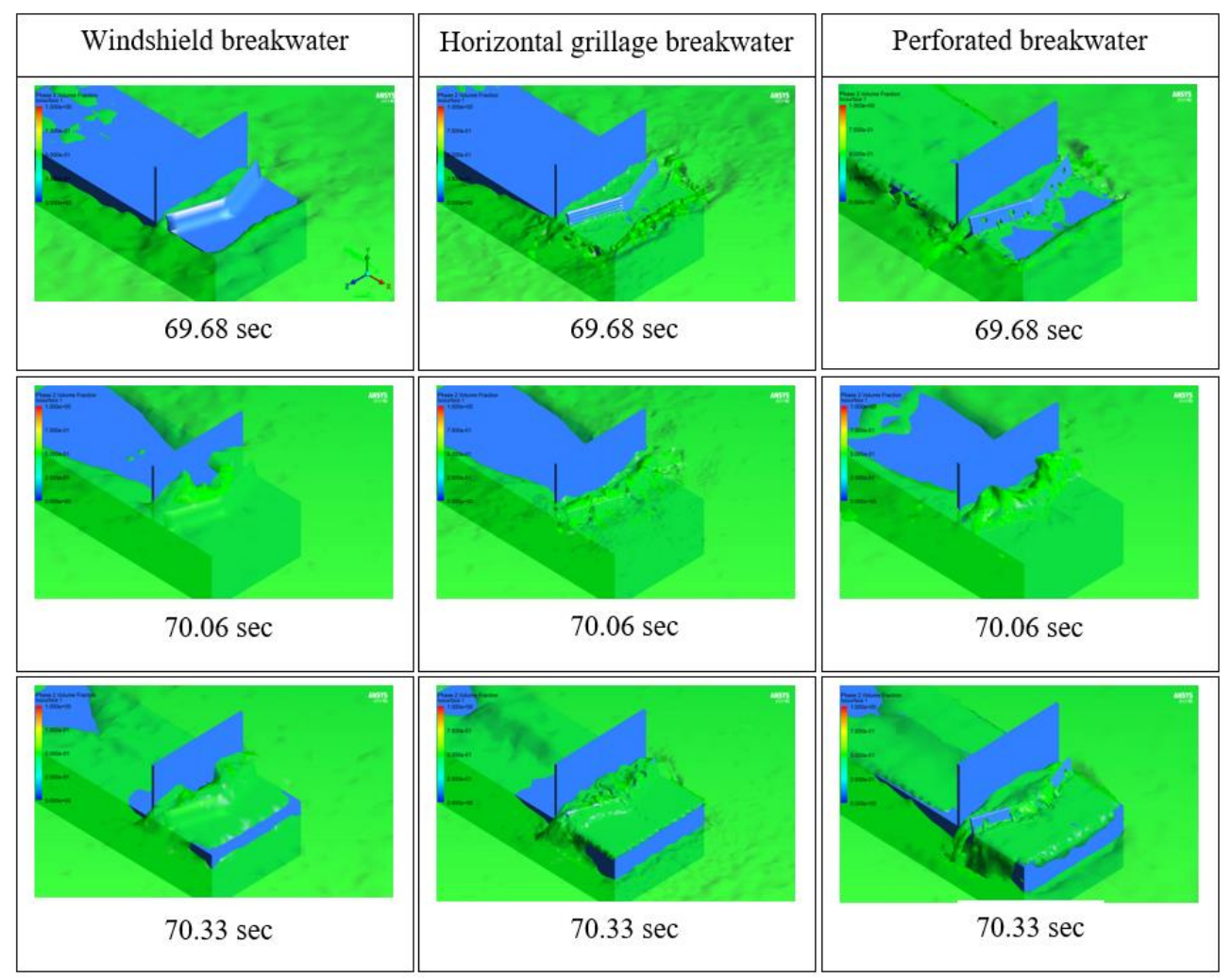

Figure 17. Greenwater splashing behaviour at various time instances for three breakwater designs.

Finally, the maximum pressures at all the pressure probes set on the vertical deck plate are compared to reach an overall understanding of the effectiveness of the breakwater designs introduced in this study. Figure 18 shows all these pressures for all four design scenarios, which again clearly establishes the effectiveness of the breakwater use over the no breakwater design. All three breakwater designs generate a similar trend in peak pressure changes at those nine locations, except at "PP1" for the perforated breakwater. That increase in pressure for this design should be associated with the locations of the perforations. However, further studies are required in this regard to confirm this conclusion. Apart from that one exception, the perforated breakwater design appears to be quite efficient in minimizing greenwater loading effects.

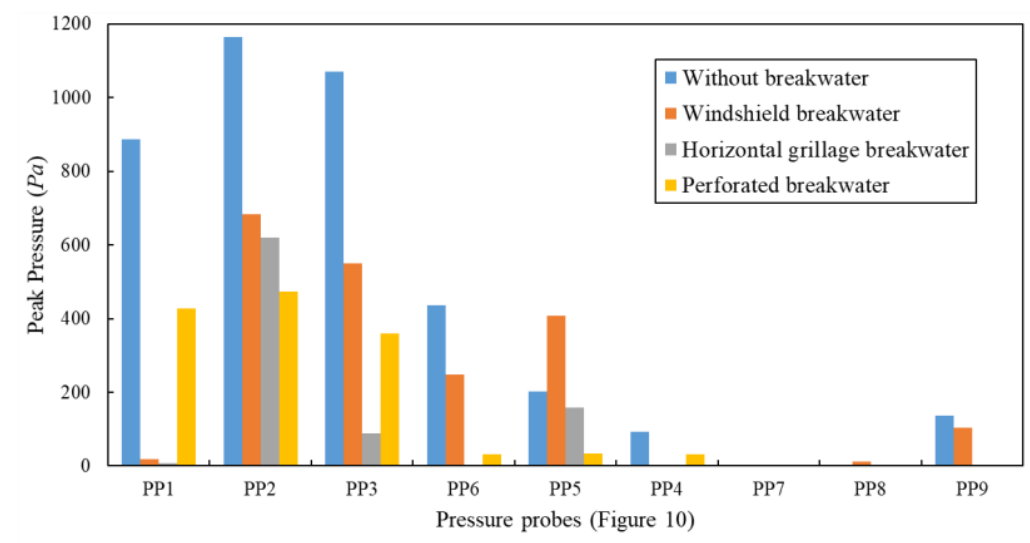

Figure 18. Comparison of peak pressure at all the pressure probes set on the vertical deck plate.

Interestingly, the pressure recorded at "PP5" on the windshield breakwater shows a much higher pressure than the simulation without breakwater. The other two designs also 
show a rise in pressure at this point. This sudden surge in pressure can be supported by the conclusion made by Pham and Varyani [23]. In their analyses, it was noted that the confronting angle of breakwater increased the take-off angle of the over-riding water jet after it impacted the breakwater. Henceforth, the substantial rise in the pressure at "PP5" is due to the design of the windshield breakwater as it does not have any penetrations or perforations as compared with the other two designs. These can be justified by the two left and right bulges of water hitting the "PP5" locations at $70.06 \mathrm{~s}$ and $70.33 \mathrm{~s}$ timesteps for the windshield breakwater snapshot in Figure 16.

\section{Conclusions}

Three different breakwater designs are proposed to minimize the impact of greenwater splashing on deck structures for ship-shaped vessels. Generally, all three designs are proven effective against greenwater loading effects. However, among the three designs, the horizontal grillage and perforated breakwaters were found to be more efficient in reducing the greenwater loading than the windshield breakwater. Nevertheless, there are pros and cons for both horizontal grillage and perforated breakwater designs. As discussed, the horizontal grillage breakwater has better performance in reducing the pressure at locations nearer to the deck, while the perforated breakwater has better performance in reducing the pressure above the deck areas. Thus, the application of these two breakwater designs will be subjected to the locations of the intended protected bow structures. Besides, it should also be noted that only one level of greenwater is considered in this study, and the trends might vary as the greenwater becomes less or more violent.

It is known that reducing greenwater loading effects requires complex analysis involving multiple parameters, for example, deck shape, motions of the ship, freeboard, wave conditions, location and the height of the breakwater on deck. In this paper, only the fundamental relations between greenwater effects and a few breakwater designs are assessed. Further simulation and experimental studies are recommended, considering all relevant parameters, as mentioned above, to evaluate the effectiveness of the breakwaters more comprehensively. Examples include a performance analysis in terms of structural aspects of the breakwaters to determine the structural integrity and materials for construction; a parametric study on optimizing the dimensions and locations of perforations on the breakwaters, analysing the flow physics for horizontal grillage breakwater design to understand the abrupt changes in the pressure behaviour; a parametric study to optimize the height and location of the breakwaters on the deck.

Author Contributions: Conceptualization, methodology, L.J.A.; software, validation, formal analysis, investigation, L.J.A. and M.A.H.; resources, data curation, writing-original draft preparation, L.J.A.; writing-review and editing, M.A.H.; visualization, supervision, M.A.H.; project administration, M.A.H.; funding acquisition, not applicable. All authors have read and agreed to the published version of the manuscript.

Funding: This research received no external funding.

Institutional Review Board Statement: Not applicable.

Informed Consent Statement: Not applicable.

Data Availability Statement: All data reported in the manuscript.

Acknowledgments: This work is part of a thesis that was submitted by the first author to the Newcastle University for partial fulfillment of his degree programme.

Conflicts of Interest: The authors declare no conflict of interest. 


\begin{tabular}{lll}
\multicolumn{2}{l}{ Nomenclature } \\
Symbol & Description & Units \\
$\lambda$ & Wavelength & $\mathrm{m}$ \\
$A_{W}$ & Wave amplitude & $\mathrm{m}$ \\
$\mathrm{H}_{\mathrm{W}}$ & Wave height & $\mathrm{m}$ \\
$\mathrm{k}$ & Wave steepness & - \\
$\mathrm{D}$ & Depth of model & $\mathrm{m}$ \\
$\mathrm{f}$ & Freeboard of the model & $\mathrm{m}$ \\
$\mathrm{L}$ & Length of the model & $\mathrm{m}$ \\
$\mathrm{B}$ & Breadth of the model & $\mathrm{m}$ \\
$\mathrm{Bt}$ & Breadth of the towing tank & $\mathrm{m}$ \\
$\mathrm{d}$ & Depth of water & $\mathrm{mm}$ \\
$\mathrm{tp}$ & Thickness of plate & $\mathrm{mm}$ \\
$\mathrm{hp}$ & Height of plate & $\mathrm{mm}$ \\
$\theta$ & Confronting angle & degree \\
$\gamma$ & Inclination angle & degree \\
$\mathrm{H}$ & Height of breakwater & $\mathrm{mm}$
\end{tabular}

\section{References}

1. Newton, R. Wetness related to freeboard and Flare. Summer Meeting RINA. Trans. RINA 1960, 102, 49-81.

2. Tasaki, R. On the Shippping Water in Head Waves. J. Zosen Kiokai 1960, 107, 47-54. [CrossRef]

3. Ochi, M. Extreme behaviour of a ship in rough seas slamming and shipping of green water. In David Taylor Model Basin, Naval Ship Research and Development Center, Washington DC, USA, Paper 2 of the Annual Meeting of the Society of Naval Architects and Marine Engineers; SNAME: Alexandria, VA, USA, 1964.

4. Buchner, B. Green Water on Ship-type Offshore Structures. Ph.D. Thesis, Delft University of Technology, Delft, The Netherlands, 2002.

5. Ersada, G.; Kvitrud, A. Green water incidents on Norwegian production ships. In Proceedings of the Tenth International Conference on Offshore and Polar Engineering (ISOPE 2000), Seattle, WA, USA, 28 May-2 June 2000; Volume 1, pp. $211-218$.

6. Morris, W.D.M.; Millar, J.; Buchner, B. Green water susceptibility of North Sea FPSO/FSUs. In Proceedings of the 15th Conference on Floating Production System (FPS), London, UK, 1 December 2000.

7. Han, J.; Lee, S.; Jeong, S. Physics of green water of FPSOs. In Proceedings of the Annual Spring Meeting; The Society of Naval Architects of Korea: Seoul, Korea, 2004; pp. 332-337. (In Korean).

8. Kim, Y.J.; Shin, K.S.; Heo, J.H.; Suh, Y.S.; Kim, W.S.; Ha, T.B.; Ha, Y.R.; Choo, K.D.; Park, K.W.; Kim, D.W.; et al. Numerical calculation and experiment of green water on the bow deck. In Proceedings of the Annual Autumn Meeting; The Society of Naval Architect of Korea: Seoul, Korea, 2004. pp. 105-114. (In Korean).

9. Hannan, M.A.; Bai, W. Nonlinear hydrodynamic responses of submerged moving payload in vicinity of a crane barge in waves. Mar. Struct. 2015, 41, 154-179. [CrossRef]

10. Hannan, M.A. Numerical Simulation of Submerged Payload Coupled with Crane Barge in Waves. Ph.D. Thesis, National University of Singapore, Singapore, 2014.

11. Pham, X.P.; Varyani, K.S.; Crossland, P. Application of Three-Dimensional Discrete Element Method in the Prediction of Deck Loading due to Green Water Effect; MARNET Workshop: Gosport, UK, 2003.

12. Iglesias, A.S.; Rojas, L.P.; Rodriguez, R.Z. Simulation of anti-roll tanks and sloshing type problems with smoothed particle hydrodynamics. Ocean. Eng. 2004, 31, 1169-1192. [CrossRef]

13. Koshizuka, S.; Shibata, K. Numerical analysis of wave impact on ships with deck wetness using a particle method. In Proceedings of the 15th International Offshore and Polar Engineering Conference, Seoul, Korea, 19-24 June 2005.

14. Pham, X.; Varyani, K. Evaluation of green water loads on high-speed containership using CFD. Ocean Eng. 2005, 32, 571-585. [CrossRef]

15. Lee, G.N.; Jung, K.H.; Chae, Y.J.; Park, I.R.; Chung, Y.S.; Malenica, S. Experimental and numerical study of the behaviour and flow kinematics of the formation of green water on a rectangular structure. Brodogradnja 2016, 67, 133-145. [CrossRef]

16. Liu, S.; Gatin, I.; Obhrai, C.; Ong, M.C.; Jasak, H. CFD simulations of violent breaking wave impacts on a vertical wall using a two-phase compressible solver. Coast. Eng. 2019, 154, 103564. [CrossRef]

17. Chen, L.; Zhang, X.; Taylor, P.H.; Draper, S.; Wolgamot, H. CFD Modelling to Investigate Design of a Whaleback-Type Forecastle for Greenwater Protection. In Proceedings of the ASME 2019 38th International Conference on Ocean, Offshore and Arctic Engineering, Glasgow, UK, 9-14 June 2019.

18. Chen, L.; Wang, Y.; Wang, X.; Cao, X. 3D Numerical Simulations of Green Water Impact on Forward-Speed Wigley Hull Using Open Source Codes. J. Mar. Sci. Eng. 2020, 8, 327. [CrossRef]

19. Lim, H.-J.; Lee, H.-H.; Park, S.-H.; Rhee, S.-H. Experiments and Numerical Validation for FPSO Bow Water Shipping. J. Soc. Nav. Arch. Korea 2012, 49, 6-13. [CrossRef] 
20. Wang, G.; Spong, R. Experience based data for FPSO's structural design. In Proceedings of the Offshore Technology Conference, Houston, TX, USA, 5-8 May 2003.

21. Barcellona, M.; Simos, M.; Greco, M.; Faltinsen, O. An Experimental Investigation on Bow Water Shipping. J. Ship Res. 2003, 47, 327-346. [CrossRef]

22. DNV, G.L. Rules for classification. Ships Navig. Ice 2016, 726.

23. Varyani, K.; Hodgson, T.; Pham, X. Effective and Efficient Breakwater Design for Trading Vessels and FPSOS. J. Offshore Mech. Arct. Eng. 2008, 130, 021004. [CrossRef]

24. ANSYS. Fluent 2020R2 Theory Guide. 2020. Available online: https:/ / ansyshelp.ansys.com/ (accessed on 2 February 2021).

25. Pham, X.P. Green Water and Loading on High-speed Containerships. Ph.D. Thesis, University of Glasgow, Glasgow, UK, 2008. 